\title{
Isolation, Classification and Nutritional Requirements of Cellulolytic Cocci in the Sheep Rumen
}

\author{
By B. D. W. JARVIS* AND E. F. ANNISON \\ Department of Biochemistry and Nutrition, University of New England, \\ Armidale, N.S.W., Australia
}

(Accepted for publication 30 December 1966)

\section{SUMMARY}

Twenty-five strains of cellulolytic cocci were isolated from the rumen contents of seven sheep, over a period of two years. Six sheep were maintained at roughly constant body weight on chaffed lucerne hay or a lucerne chaff/oat chaff mixture. One strain was obtained from an animal on a low protein diet.

The bacteria were classified as Ruminococcus albus or $R$. flavifaciens by the accepted monothetic classification. Morphological, cultural, nutritional and fermentation data were then used to classify them by a numerical method. It was concluded that the numerical classification of these strains agreed closely with the classification by more established methods, but justified the assignment of relationship between members of the same species.

The nutritional characteristics of 11 strains capable of growth in partially defined medium were investigated. An organic nitrogen source was essential for three strains; the remaining eight strains grew better with casein hydrolysate than with ammonium sulphate as the sole nitrogen source. Although ammonium ions were not essential for growth, only three strains were capable of growth in the absence of volatile fatty acids. $\mathrm{CO}_{2}$ was essential for 10 of 11 strains.

\section{INTRODUCTION}

The development of adequate cultural methods (Hungate, 1950; Sijpesteijn, 1948) has permitted the isolation and classification of cellulolytic rumen bacteria. Two species of cellulolytic cocci have been established, Ruminococcus flavifaciens and R. albus (Sijpesteijn, 1951; Hungate, 1957; Bryant, Small, Bouma \& Robinson, 1958b). Nutritional studies of ruminococci in pure culture showed that most strains required branched or straight chain volatile fatty acids as growth factors and utilized ammonium nitrogen in preference to amino acids for protein synthesis (Bryant \& Robinson, $1961 b$ ).

This paper describes the isolation and classification of 25 strains of ruminococci from sheep and the nutritional characteristics of eleven strains capable of growth in chemically defined medium.

\section{METHODS}

Sheep. Six merino sheep from three commercial flocks in the New England district of New South Wales were placed on diets which would maintain them at roughly constant body weight. The sheep varied in age from 4 to 8 years and included ewes and

* Present address: Department of Bacteriology, University of California, Davis, California 95616. 
wethers. A permanent rumen fistula was established in each sheep. The sheep were housed indoors in separate pens on a slatted floor. Sheep C6, C18, C76, C83 and C114 were fed $800 \mathrm{~g}$. lucerne chaff at 9.00 a.m. daily. C2 received $200 \mathrm{~g}$. lucerne chaff $+600 \mathrm{~g}$. oat chaff daily. A seventh sheep, C3, received $500 \mathrm{~g}$. low protein diet (See Table 1). All sheep except C3 had been established on their rations more than 6 months before bacterial isolations were made. Sheep C 3 was changed from lucerne to the low protein diet 6 weeks before sampling. The sheep had access to water at all times.

Isolation of ruminococci. Ruminococci were isolated from rumen contents by using the anaerobic roll-tube technique described by Hungate (1950), with the following modifications. Commercial $\mathrm{CO}_{2}$ was freed from $\mathrm{O}_{2}$ by passing it over heated reduced copper gauze. Rumen liquor was obtained approximately $8 \mathrm{hr}$. after feeding, strained through two thicknesses of cheesecloth, and collected in a $150 \mathrm{ml}$. centrifuge bottle. Air was excluded by completely filling the bottle, and closing it with a rubber stopper. The bottle was then held overnight at $2^{\circ}$ and centrifuged at $1200 \mathrm{~g}$ for $10 \mathrm{~min}$. before use. The medium used was a modification of the enrichment medium described by Halliwell (1957), having the following composition (g./100 ml.): $\mathrm{KCl}, 0.04 ; \mathrm{KH}_{2} \mathrm{PO}_{4}$, $0.018 ; \mathrm{MgSO}_{4} .7 \mathrm{H}_{2} \mathrm{O}, 0.03$; yeast extract (Difco), 0.03; indigo disulphonate, 0.0005; agar (Bacto no. 1), 1.35; $\left(\mathrm{NH}_{4}\right)_{2} \mathrm{HPO}_{4}, 0.09 ; \mathrm{CaCl}_{2} .6 \mathrm{H}_{2} \mathrm{O}, 0.06 ; \mathrm{NaHCO}_{3}, 0.375$; cysteine $\mathrm{HCl} . \mathrm{H}_{2} \mathrm{O}, 0.05 ; \mathrm{Na}_{2} \mathrm{~S} .9 \mathrm{H}_{2} \mathrm{O}, 0.025$; rumen liquor $20.0 \%(\mathrm{v} / \mathrm{v})$. The first six ingredients were weighed out, made up with a boiled-out water and rumen liquor, then autoclaved at $121^{\circ}$ for $15 \mathrm{~min}$. The flask was cooled to $45^{\circ}$ and the remaining ingredients added as Seitz-filtered solutions under $\mathrm{O}_{2}$-free $\mathrm{CO}_{2}$ or $\mathrm{N}_{2}$. Sterile medium (9 ml.) was dispensed in $25 \mathrm{~mm} . \times 150 \mathrm{~mm}$. test tubes under $\mathrm{CO}_{2}$. Each tube contained a piece of sterile filter paper (Ekwip no. 1, Industrial Equipment (A/sia) Pty, Ltd., Sydney). A sterile solution of cysteine $\mathrm{HCl}$ and $\mathrm{Na}_{2} \mathrm{~S} .9 \mathrm{H}_{2} \mathrm{O}$ was prepared (Bryant \& Robinson, 1961c) and added to the tubes immediately before inoculation. This medium is referred to subsequently as modified Halliwell agar. When cellobiose agar was required, the filter paper was omitted and cellobiose $0.5 \%(\mathrm{w} / \mathrm{v})$ was added to the medium as a Seitz-filtered solution before it was dispensed.

A decimal dilution series of eight tubes was set up for each sample of rumen content in modified Halliwell agar. The first tube was opened under a stream of $\mathrm{CO}_{2}$ and a wide-mouthed pipette was used to transfer $1 \mathrm{ml}$. of whole rumen contents to it; the tube was then closed and its contents thoroughly mixed. Subsequent transfers were made through the stoppers by using $2 \mathrm{ml}$. Luer-Lok syringes fitted with $1 \frac{3}{8}$ in. no. 18 needles. The plunger was removed and the syringe flushed with sterile $\mathrm{CO}_{2}$ immediately before use and a fresh syringe was used for each dilution. Cellulolytic organisms were recognized by their ability to produce visible colonies and digestion on filter paper within 4 days at $38 \cdot 5^{\circ}$. New strains were isolated from $10^{-6}$ dilutions so that they could be considered true rumen organisms (Gall \& Huhtanen, 1951). Strains were purified by passage through the following sequence of subcultures on modified Halliwell agar : filter paper agar $\rightarrow$ cellobiose agar $\rightarrow$ filter paper agar $\rightarrow$ cellobiose agar. At each stage the isolate was serially diluted and subsequent inocula derived from tubes which showed well-isolated colonies. Colonies developing in the second series of cellobiose agar cultures usually showed no cultural or microscopic evidence of impurity and were capable of growth on filter paper strips.

Maintenance of cultures. Cultures in current use were maintained on filter paper 
agar and subcultured every 4-8 days. For prolonged storage, infected filter paper was used to inoculate cellobiose agar slopes which were incubated for $48 \mathrm{hr}$ at $38.5^{\circ}$, sealed with a mixture of 3 parts petroleum jelly to 1 part paraffin wax, quick-frozen by immersion in liquid air, and stored at $-25^{\circ}$ to $-30^{\circ}$ in a deep-freeze cabinet.

Gram reaction and morphological arrangement. Slides were prepared from the water of syneresis exuded from cultures on modified Halliwell agar containing $0.25 \%$ cellobiose after $15-24 \mathrm{hr}$. incubation at $38 \cdot 5^{\circ}$.

Pigment production. Pigment production was recorded after 4 days incubation on filter paper strips in modified Halliwell agar. The pigment was classified as light yellow (LY), dark yellow (DY), or absent (DZ).

Production of gas. The formation of bubbles in solid media or excessive pressure in vessels containing liquid media was recorded as evidence of gas production.

Fermentation of carbohydrates and the final $\mathrm{pH}$ values of cultures. The basal medium for these tests was the weakly buffered $20 \%$ (v/v) rumen fluid medium under $10 \%(\mathrm{v} / \mathrm{v})$ $\mathrm{CO}_{2}$ in $\mathrm{N}_{2}$ described by Bryant et al. (1958a).

With the exception of xylan, the substrates were freshly prepared as $5 \%(\mathrm{w} / \mathrm{v})$ solutions in boiled-out distilled water under $\mathbf{N}_{2}$. A Luer-Lok syringe fitted with a Swinney adaptor containing a membrane filter (code no. G.S., Millipore Filter Corp., Bedford, Mass., U.S.A.) was used to sterilize each solution as it was added to the medium. Xylan (50 mg.) was weighed out in $15 \mathrm{~mm} . \times 150 \mathrm{~mm}$. test-tubes which were plugged with cotton wool and autoclaved at $121^{\circ}$ for $15 \mathrm{~min}$. The basal medium was prepared, autoclaved and dispensed into the appropriate number of xylan tubes or empty sterile tubes under an atmosphere of $10 \%(\mathrm{v} / \mathrm{v}) \mathrm{CO}_{2}$ in $\mathrm{N}_{2}$. Reducing agents (Bryant \& Robinson, $1961 c)$, sodium carbonate solution $(0.06 \%$, w/v) and substrate were added just before inoculation.

The final $\mathrm{pH}$ value was determined in basal medium containing $1 \%(\mathrm{w} / \mathrm{v})$ cellobiose. Duplicate $5 \mathrm{ml}$. quantities were inoculated for each strain and incubated for 7 days at $38.5^{\circ}$. After incubation the $\mathrm{pH}$ value of each tube was determined by using a Cambridge meter.

The following carbohydrate substrates were tested in basal medium at a final concentration of $0.5 \%(\mathrm{w} / \mathrm{v})$ analytical reagent grade $\mathrm{D}(+)$-xylose, $\mathrm{L}(+)$-arabinose, fructose, glucose, cellobiose, sucrose, lactose (Oxoid, bacteriological grade) and xylan (Mann Research Labs., Inc.). The inoculum for each strain was the drop of a 15-24 hr. culture in cellobiose broth. Controls containing inoculum but no substrate, and substrate (cellobiose) but no inoculum, were set up with each series. Cultures were incubated 7 days at $38.5^{\circ}$. A marked decrease in $\mathrm{pH}$ value relative to the controls indicated that a substrate had been utilized.

Fermentation products. Small fragments of infected filter paper were used to inoculate flasks containing $100 \mathrm{ml}$. quantities of $20 \%$ (v/v) rumen liquor broth (Bryant et al. 1958 a) modified to obtain a higher buffer capacity by using $100 \% \mathrm{CO}_{2}$ and $0.4 \%$ (w/v) $\mathrm{Na}_{2} \mathrm{CO}_{3}$. Each strain was inoculated into medium with and without substrate $\left(1 \%, \mathrm{w} / \mathrm{v}\right.$, Ekwip no. 1 filter paper). After incubation at $38.5^{\circ}$ for 4 weeks the products of cellulose fermentation were measured, corrections being made for the volatile fatty acids produced in the control flasks in the absence of substrate.

Reducing sugars were determined qualitatively on the filtered fermentation liquor by Benedict's method (Hawk, Oser \& Summerson, 1954). 
Organic acids were determined by silicic acid column chromatography as described by Leng \& Annison (1963).

Ethanol was distilled from fermentation liquor (Neish, 1952) and estimated by using alcohol dehydrogenase (Bücher \& Redetski, 1951).

Growth in the absence of rumen liquor. This was usually examined by transferring one drop of a $48 \mathrm{hr}$ culture in $20 \%(\mathrm{v} / \mathrm{v})$ rumen liquor broth under $10 \%(\mathrm{v} / \mathrm{v}) \mathrm{CO}_{2}$ in $\mathrm{N}_{2}$ to $5 \mathrm{ml}$. of the complete, partially defined medium devised by Bryant \& Robinson (1961 $a$ ), but the organisms LY 2, LY 3 and LY 4 were tested on modified broth medium as described by Dehority (1963). Bryant \& Robinson (1961a) medium contained: cellobiose, casein hydrolysate, $\left(\mathrm{NH}_{4}\right)_{2} \mathrm{SO}_{4}, \mathrm{CH}_{3} \mathrm{COONa} .3 \mathrm{H}_{2} \mathrm{O}$, branched chain volatile fatty acids, vitamins, trace minerals, resazurin, cysteine $\mathrm{HCl}$ and $\mathrm{NH}_{2} \mathrm{~S}_{.9} 9 \mathrm{H}_{2} \mathrm{O}$ as reductants and a $100 \% \mathbf{C O}_{2}$-bicarbonate buffer system.

Growth in the absence of $\mathrm{CO}_{2}$. Bryant \& Robinson medium was prepared and handled under $100 \% \mathrm{~N}_{2}$. Sodium carbonate was omitted and the $\mathrm{pH}$ value was adjusted with sterile $\mathrm{CO}_{2}$-free $\mathrm{NaOH}$ solution.

Growth in the absence of organic nitrogen. Casein hydrolysate was omitted from the Bryant \& Robinson medium containing B vitamins and cysteine $\mathrm{HCl}$ prepared under $100 \% \mathrm{CO}_{2}$.

Growth in the absence of $\left(\mathrm{NH}_{4}\right)^{+}$. Aqueous solutions of casein hydrolysate were freed from traces of $\left(\mathrm{NH}_{4}\right)^{+}$by adjustment to $\mathrm{pH} 10$ with $20 \% \mathrm{NaOH}$ and vigorous gassing with a stream of $\mathrm{N}_{2}$ for $90 \mathrm{~min}$.; the solution was then readjusted to $\mathrm{pH} 7 \cdot 0$ by adding a few drops of concentrated $\mathrm{HCl}$ and the remaining solid ingredients of Bryant \& Robinson medium were added. $\mathrm{Na}_{2} \mathrm{SO}_{4}$ replaced $\left(\mathrm{NH}_{4}\right)_{2} \mathrm{SO}_{4}$.

Growth in the absence of volatile fatty acids. Bryant \& Robinson medium was prepared under $100 \% \mathrm{CO}_{2}$ omitting acetate, isobutyrate, $\alpha$-methyl- $n$-butyrate, valerate and isovalerate.

Batches of six to eight cultures were inoculated in duplicate for each of the deficient media and a complete medium control. After inoculation each tube was dipped in a mixture of petroleum jelly and paraffin wax $(1+1)$ to prevent the entry of oxygen. Cultures were incubated at $38.5^{\circ}$ and inspected daily for turbidity. Tubes which became turbid were examined microscopically and recorded as positive when the expected morphological type was found.

\section{RESULTS}

Table 1 relates the strains isolated to the diets of the sheep from which they were isolated, and to the date of isolation.

The microbiological characteristics of these strains are recorded in Table 2. The Gram reaction was variable in nine of the twenty-five strains; changes of this kind were reported by Bryant (1963). Some strains showed a series of changes with age. For instance, strains DZ2 and D24 changed from strongly Gram-positive to Gramvariable and became Gram-negative after 7 days of incubation.

Approximately half the strains (14/25) were able to grow in Bryant \& Robinson (1961 a) medium. This permitted a more detailed study of the nutritional requirements of eleven strains recorded in Table 3. All strains grew in the absence of $\left(\mathrm{NH}_{4}\right)_{2} \mathrm{SO}_{4}$ and utilized casein hydrolysate as a source of nitrogen, but three strains failed to grow when $\left(\mathrm{NH}_{4}\right)_{2} \mathrm{SO}_{4}$ was the sole nitrogen source, casein hydrolysate being omitted. 
A majority of strains required volatile fatty acids; only strains LY 10, LY 11 and DZ4 were able to grow in their absence. Only one strain (LY 10) grew when carbonate was omitted from the medium.

Table 1. Origins of the cellulolytic bacteria isolated from sheep rumens

$\begin{array}{ccccc} & \begin{array}{c}\text { Sheep } \\ \text { identification } \\ \text { code }\end{array} & \begin{array}{c}\text { Date } \\ \text { sampled }\end{array} & \begin{array}{c}\text { Time } \\ \text { sampled }\end{array} & \begin{array}{c}\text { Strain } \\ \text { code }\end{array} \\ \text { Sheep diet } & \text { no. }\end{array}$

Group I. Gram-positive or Gram-negative cocci in pairs or singly, 11 strains

Lucerne chaff ( $800 \mathrm{~g}$./day)

\begin{tabular}{|c|c|c|c|}
\hline C. 6 & $\begin{array}{l}\text { 29. v. } 63 \\
\text { 17. x. } 63 \\
\text { 17. x. } 63 \\
\text { 18. xi. } 64 \\
\text { 18. i. } 65 \\
\text { 18. ii. } 65\end{array}$ & $\begin{array}{l}\overline{-} \\
\overline{-} \\
4.20 \\
5.00 \\
4.30\end{array}$ & $\begin{array}{l}\text { LY2 } \\
\text { LY 3 } \\
\text { LY4 } \\
\text { LY5 } \\
\text { LY11 } \\
\text { LY } 23\end{array}$ \\
\hline C.18 & $\begin{array}{r}\text { 29. i. } 65 \\
\text { 1. ii. } 65\end{array}$ & $\begin{array}{l}3.00 \\
3.00\end{array}$ & $\begin{array}{l}\text { LY } 16 \\
\text { LY17 }\end{array}$ \\
\hline C.76 & $\begin{array}{l}\text { 14. i. } 65 \\
\text { 18. i. } 65\end{array}$ & $\begin{array}{l}3.00 \\
8.00\end{array}$ & $\begin{array}{l}\text { LY } 9 \\
\text { LY } 12\end{array}$ \\
\hline 114 & 8. ii. 65 & 9.00 & LY 21 \\
\hline
\end{tabular}

Group II. Gram-negative cocci in long chains frequently over 20 units, 8 strains

\begin{tabular}{|c|c|c|c|c|}
\hline \multirow[t]{5}{*}{ Lucerne chaff ( $800 \mathrm{~g} . / \mathrm{day})$} & C.6 & $\begin{array}{l}\text { 18. xi. } 64 \\
\text { 14. i. } 65\end{array}$ & $\begin{array}{l}4.20 \\
4.15\end{array}$ & $\begin{array}{l}\text { LY } 7 \\
\text { LY } 10\end{array}$ \\
\hline & C.18 & $\begin{array}{l}\text { 3. xii. } 64 \\
\text { 22. ii. } 65\end{array}$ & $\begin{array}{l}9.30 \\
7.30\end{array}$ & $\begin{array}{l}\text { LY } 8 \\
\text { LY } 24\end{array}$ \\
\hline & C.76 & $\begin{array}{l}\text { 18. i. } 65 \\
\text { 18. ii. } 65\end{array}$ & $\begin{array}{l}8.00 \\
4.30\end{array}$ & $\begin{array}{l}\text { LY } 13 \\
\text { LY } 22\end{array}$ \\
\hline & C.83 & 8. ii. 65 & 8.30 & LY20 \\
\hline & C.114 & 27. i. 65 & 4.15 & LY14 \\
\hline \multicolumn{5}{|c|}{ up III. Gram-variable cocci in short chains } \\
\hline Lucerne chaff ( $800 \mathrm{~g} . /$ day) & C.6 & $\begin{array}{l}\text { 4. ii. } 65 \\
\text { 4. ii. } 65\end{array}$ & $\begin{array}{l}7.30 \\
7.30\end{array}$ & $\begin{array}{l}\text { LY } 18 \\
\text { LY } 19\end{array}$ \\
\hline \multicolumn{5}{|c|}{ oup IV. Gram-negative cocci in short chains 8-10 units } \\
\hline $\begin{array}{l}\text { Oat chaff }(600 \mathrm{~g} . / \text { day })+\text { lucerne } \\
\text { chaff }(200 \mathrm{~g} . / \text { day })\end{array}$ & C.2 & 17. viii. 64 & 9.30 & DY 2 \\
\hline Low protein $\operatorname{diet}^{*}(500 \mathrm{~g} . /$ day $)$ & C.3 & 19. viii. 64 & 3.00 & DY 1 \\
\hline \multicolumn{5}{|c|}{ up V. Large Gram-positive cocci in clumps and pairs } \\
\hline $\begin{array}{l}\text { Oat chaff }(600 \mathrm{~g} . / \text { day })+\text { lucerne } \\
\text { chaff }(200 \mathrm{~g} . / \text { day })\end{array}$ & $\begin{array}{l}\text { C. } 2 \\
\text { C.2 }\end{array}$ & $\begin{array}{l}\text { 9. viii. } 64 \\
\text { 18. xi. } 64\end{array}$ & $\begin{array}{l}3.30 \\
4.30\end{array}$ & $\begin{array}{l}\text { Dz2 } \\
\text { Dz4 }\end{array}$ \\
\hline
\end{tabular}

* Low protein diet, $1,450 \mathrm{~g}$. wheat straw; $50 \mathrm{~g}$. lucerne chaff; $7.5 \mathrm{~g}$. calcium phosphate; $1.5 \mathrm{~g}$ sodium chloride; $5.0 \mathrm{~g}$. Premix ( $\mathrm{Fe}, \mathrm{I}, \mathrm{Cu}, \mathrm{Co}, \mathrm{Zn}, \mathrm{Mn}$, vitamins $\mathrm{A}$ and $\mathrm{D}$ ).

The carbohydrates fermented by six strains of ruminococci are recorded in Table 4. Each strain was tested in duplicate on more than one occasion. The results with xylose, arabinose, cellobiose and xylan were reproducible for all strains, but the fermentation of glucose, sucrose, lactose and fructose was not a reproducible property of these strains. 


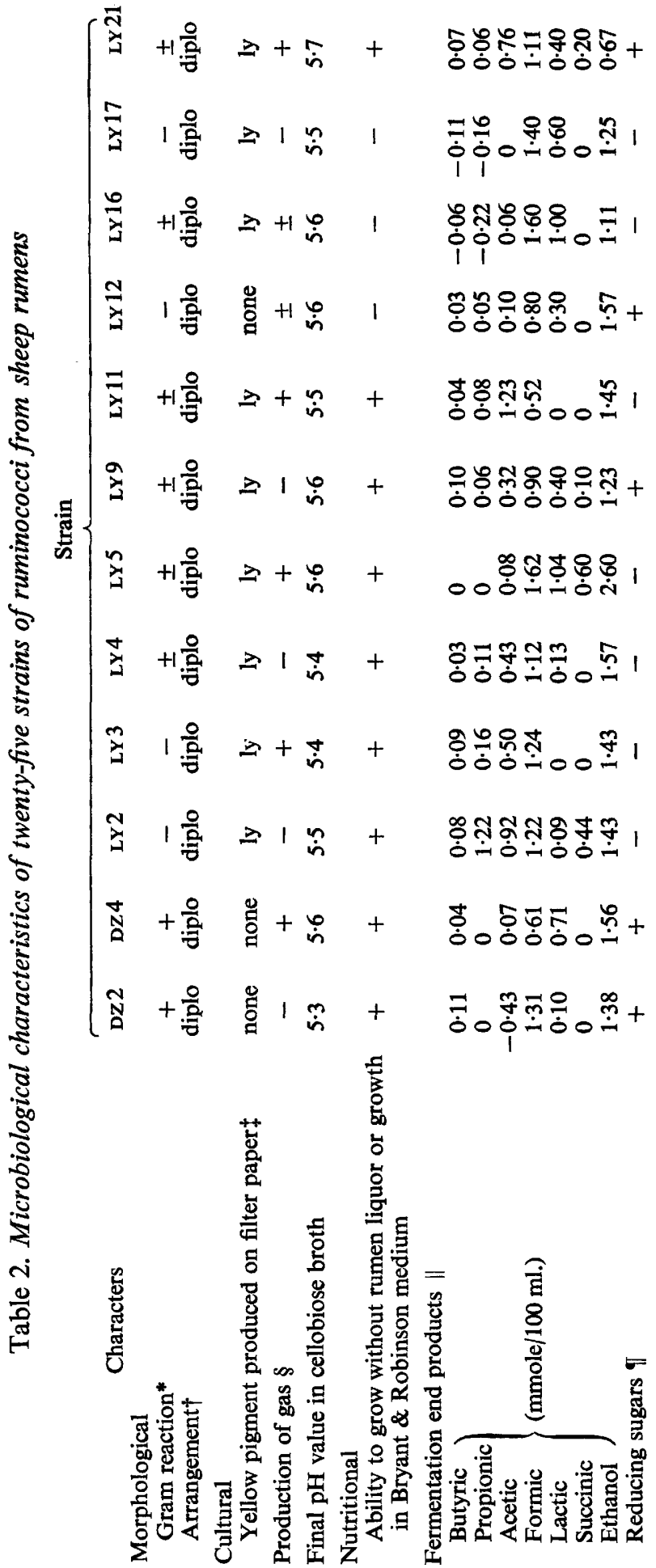




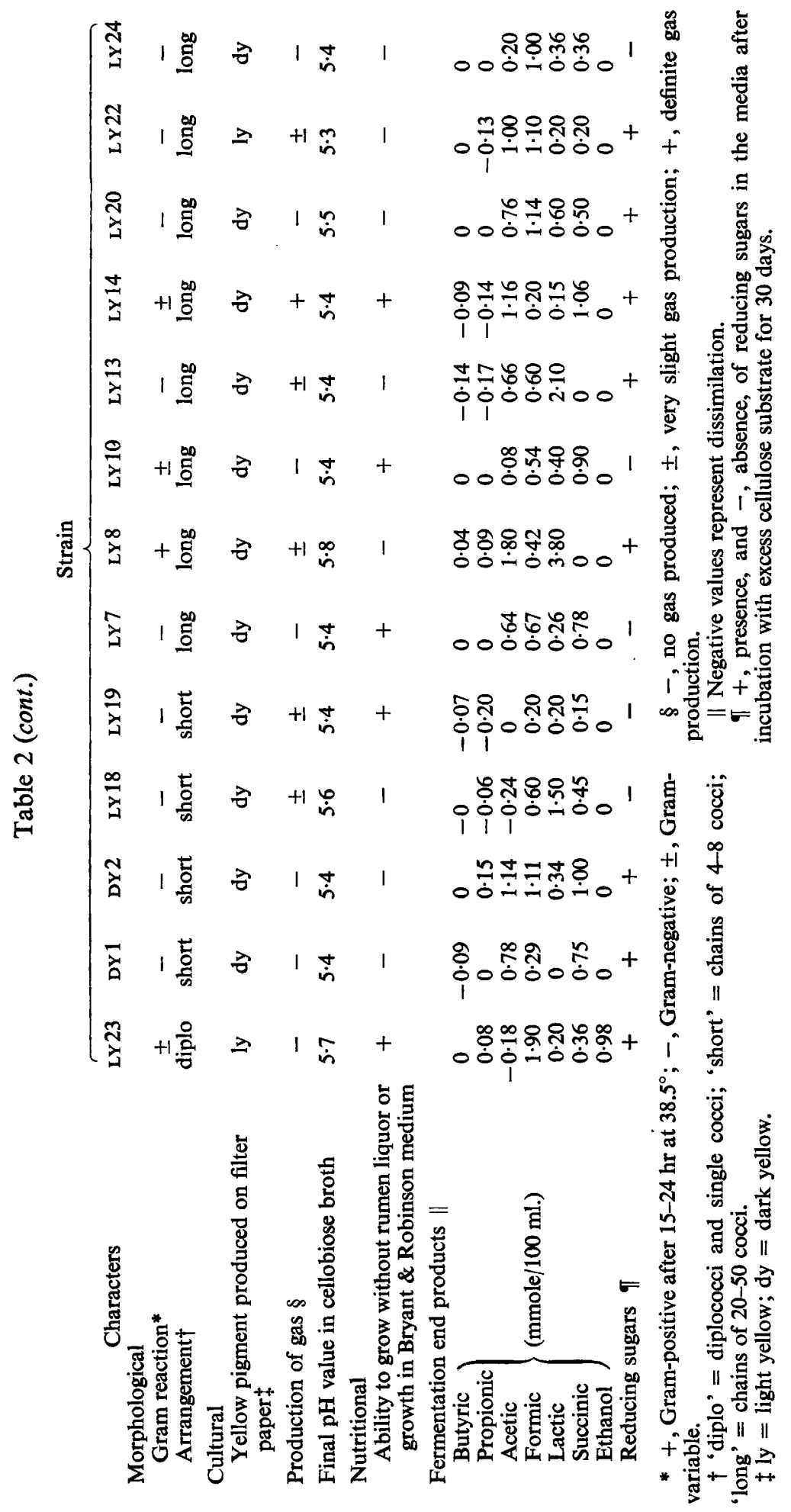


Table 3. The growth of sheep-rumen ruminococci in various nutritionally deficient media

\begin{tabular}{|c|c|c|c|c|c|}
\hline \multirow[b]{2}{*}{ Strain no. } & \multicolumn{5}{|c|}{ Bryant \& Robinson medium } \\
\hline & Complete & $\begin{array}{l}\text { Without } \\
\left(\mathrm{NH}_{4}\right)+\end{array}$ & $\begin{array}{c}\text { Without casein } \\
\text { hydrolysate }\end{array}$ & $\begin{array}{l}\text { Without volatile } \\
\text { fatty acids }\end{array}$ & $\begin{array}{l}\text { Without } \\
\left(\mathrm{CO}_{3}\right)^{2-}\end{array}$ \\
\hline $\mathrm{Dz} 2$ & $+*$ & + & + & - & - \\
\hline Dz4 & + & + & + & + & - \\
\hline LY 4 & + & + & + & - & - \\
\hline LY 5 & + & + & + & - & \pm \\
\hline LY9 & + & + & - & \pm & \pm \\
\hline LY 10 & + & + & + & $\bar{t}$ & + \\
\hline LY 11 & + & + & + & + & \pm \\
\hline LY 14 & + & + & - & \pm & - \\
\hline LY 19 & + & + & - & \pm & - \\
\hline LY 21 & + & + & + & - & - \\
\hline LY 23 & + & + & + & - & - \\
\hline
\end{tabular}

* A positive result denotes that the strain grew freely in the medium. Negative results denote a failure to produce a significant increase in turbidity. In the case of results recorded \pm , the result is uncertain. The growth in these cases was sparse and frequently did not occur in both duplicates.

Table 4. Carbohydrate fermented by strains of sheep-rumen ruminococci

\begin{tabular}{lcccccc}
\multicolumn{7}{c}{ Strain } \\
$\quad$ Sugar & LY2 & LY3 & LY4 & DZ2 & DY1 & DY2 \\
Xylose & --- & --- & -- & -- & --- & --- \\
Arabinose & --- & --- & --- & -- & +++ & \pm++ \\
Fructose & ++ \pm & +- \pm & +-- & -- & +++ & --- \\
Glucose & +++ & \pm-- & +-- & -- & --+ & --+ \\
Lactose & ++- & --- & --- & -- & --+ & --- \\
Sucrose & \pm+ \pm & \pm-- & +-- & -- & - \pm+ & \pm-- \\
Cellobiose & +++ & +++ & +++ & ++ & +++ & +++ \\
Xylan &.+ & +++ & +++ & ++ & +++ & +++
\end{tabular}

* Each result represents a pair of duplicates. The three columns for each strain indicate the results obtained on three separate occasions. A definite decrease in $\mathrm{pH}$ value relative to the controls is denoted by a positive sign. A decrease in $\mathrm{pH}$ value in one member of a pair is recorded as \pm . A negative sign indicates that no change in $\mathrm{pH}$ occurred. . = no test

\section{Nutritional requirements of ruminococci}

In preliminary trials Bryant \& Robinson $(1961 a)$ found 10 of 15 strains capable of growth in their complete, partially defined medium. Seven of these were Ruminococcus albus and three $R$. flavifaciens. In the present study 14 of 25 strains grew in Bryant \& Robinson medium. Of these, 10 strains were shown to be $R$. albus and four $R$. flavifaciens. These observations suggest that strains classifiable as $R$. flavifaciens are more dependent upon special growth factors in rumen fluid than those classed as $R$. albus.

The existence of ruminococcal strains which utilize $\left(\mathrm{NH}_{4}\right)^{+}$in preference to aminonitrogen is well established. $\left(\mathrm{NH}_{4}\right)^{+}$was reported to be an essential nutrient for some of the strains which have been examined (Bryant \& Robinson, $1961 b$; Bryant \& Robinson, 1962; Bryant \& Robinson, 1963; Dehority, 1963). Strains which required organic nitrogen have also been reported. Fletcher (1956) and Ayers (1958) considered casein hydrolysate to be essential for the growth of a strain of Ruminococcus albus and 
one of $R$. flavifaciens. Allison, Bryant \& Doetsch (1962) suggested that organisms capable of utilizing inorganic nitrogen in the rumen have a competitive advantage because branched chain volatile fatty acids and ammonia are more abundant in rumen contents than are amino acids and thus more readily available for protein synthesis. It seems likely that the ecological significance of these considerations is decreased in animals fed a high protein (lucerne chaff) diet, especially as the ruminococci are often closely applied to particles of ingesta which are likely to be relatively rich in organic nitrogen. The 11 strains considered here all grew readily when vitaminfree casein hydrolysate was the sole nitrogen source. In the case of strains LY4 and DZ2, growth on Bryant \& Robinson medium without $\left(\mathrm{NH}_{4}\right)^{+}$was equivalent to that in the complete Bryant \& Robinson medium after $48 \mathrm{hr}$, although at this time no growth was apparent in Bryant \& Robinson medium without casein hydrolysate. However, on further incubation, a well marked turbidity appeared in this latter medium. Strains LY4 and DZ2 grew in Bryant \& Robinson medium with an amino acid mixture as the sole nitrogen source apart from B-group vitamins and cysteine (amino acids \%, w/v: glutamic acid, 0.4; L-leucine, 0.2; DL-valine, L-lysine, DL-aspartic acid and DL-serine, 0.16 each; DL-phenylalanine, L-arginine $\mathrm{HCl}, 0.12$ each; L-histidine, 0.06). Turbidity was evident after incubation for $48 \mathrm{hr}$ for strain LY 4 and after $72 \mathrm{hr}$ for strain $\mathrm{Dz} 2$ indicating that with this restricted range of amino acids growth still occurred more readily than it did when all cellular nitrogen had to be synthesized from $\left(\mathrm{NH}_{4}\right)^{+}$. One strain of $R$. albus (LY9) and two strains of $R$. flavifaciens (LY 14, LY 19) were dependent on organic nitrogen for growth. It is concluded that the genus Ruminococcus includes strains which have an absolute requirement for organic nitrogen and strains which have a preference for organic nitrogen, as well as those for which inorganic nitrogen is an essential nutrient (Bryant \& Robinson, $1961 \mathrm{~b}$ ).

A majority of the strains were capable of synthesizing amino acids from $\left(\mathrm{NH}_{4}\right)^{+}$and $\left(\mathrm{CO}_{3}\right)^{2-}$ ions and volatile fatty acids. Presumably the mechanism was analogous to that shown to exist in Ruminococcus flavifaciens strain C94 (Allison et al. 1962; Allison \& Bryant, 1963). The strains described here could also utilize preformed amino acids and thus resembled strain B 34b of Dehority (1963); consequently volatile fatty acids were not required for amino acid synthesis. Nevertheless, only three out of the 11 strains were capable of growth in media which did not contain volatile fatty acids.

Rumen bacteria are characterized by their dependence on exogenous $\mathrm{CO}_{2}$ for growth (Bryant, 1959). Strains of ruminococci have been shown to require $\mathrm{CO}_{2}$ (Bryant \& Burkey, 1953; Dehority, 1963) and utilize it for amino acid synthesis (Allison \& Bryant, 1963). All but one of the eleven strains conformed to this pattern.

\section{Taxonomy of ruminococci}

Bryant (1963) distinguished between Ruminococcus albus and $R$. flavifaciens on the basis of morphology and fermentation product data. In the present work $\mathrm{CO}_{2}$ was not determined and production of $\mathrm{H}_{2}$ was determined only for a few strains. With these limitations the results for each strain can be compared with Bryant's specification.

The strains examined here were classified as follows:

Ruminococcus albus: 10 strains: DZ4, LY 2, LY 3, LY4, LY 5, LY 9, LY 11, LY 12, LY16, LY21.

Ruminococcus flavifaciens: 8 strains: DY 1, DY 2, LY 7, LY 10, LY 14, LY 20, LY22, LY 24. 
Intermediates similar to Ruminococcus albus: 3 strains: DZ2, LY 17, LY 23.

Intermediates similar to Ruminococcus flavifaciens: 4 strains: LY 8, LY 13, LY 18, LY 19.

Intermediates classed as 'similar to Ruminococcus albus' were grouped together on the basis of morphology, pigment produced and production of ethanol; these characteristics are held in common with $R$. albus. These intermediates were not classed as $R$. albus because they did not produce acetate as a fermentation product.

Intermediates classed as 'similar to Ruminococcus flavifaciens' grew in chains and, in common with other strains of $\boldsymbol{R}$. flavifaciens considered here, did not produce ethanol, produced little or no gas, and showed dark yellow pigmentation. Strains LY 18 and LY 19 could not be accepted as $R$. flavifaciens because acetate was not produced. Strains LY 8 and LY 13 were not acceptable because they did not produce succinate.

Ruminococcus albus. Hungate (1957) and Bryant et al. (1958b) placed some streptococci in the $R$. albus group, but in the present study only diplococci were classed as $R$. albus since only diplococci were found to produce ethanol. The $R$. albus strains were similar to those described by other workers in that the yellow pigment was pale or absent. All three sets of data agree in that most $R$. albus strains produce ethanol, acetate and formate as fermentation end products. Hungate (1957) found one strain which metabolized acetate, which was not included as typical of the $R$. albus group. In the present study three of 13 'albus'-type strains did not produce acetate. Hungate found no $R$. albus strains which produced succinate but the present results agree with Bryant et al. $(1958 b)$ who found strains which produced succinate. Strains were also found which produced lactate, a character observed by Hungate but not by Bryant et al. Hydrogen was identified as a gaseous end product for strains LY 11, LY 12, LY 16, and gas production was also observed for strains DZ4, LY 3, LY 5, LY 7; but gas production was not as general among these isolates as among those reported by Hungate (1957) and Bryant et al. (1958b). The additional strains studied here support the conclusions of Bryant et al. $(1958 b)$ about the fermentation end products produced by $R$. albus except in regard to acetate which may or may not be produced by our strains. They do not show the similarity observed by Kistner \& Gouws (1964) among 10 strains isolated from sheep on a lucerne hay diet.

Ruminococcus flavifaciens. Comparison of our strains accepted as $R$. flavifaciens with those described by Sijpesteijn (1951), Hungate (1957) and Bryant et al. (1958b) indicated that they fit the previous descriptions except that three of our strains did not produce reducing sugar when fermenting excess cellulose. The absence of ethanol from the end products was the most consistent feature of the streptococcal strains and extended to those intermediates which, on other grounds, could not be regarded as $R$. flavifaciens.

\section{Numerical classification of ruminococci}

The classification of ruminococci applied in the preceding paragraphs is based on their biochemical and morphological characteristics. Successive investigators have relaxed these criteria to accommodate strains which exhibited all but one or two of the characteristics required of the species. It has never been shown that the two 'species', Ruminococcus albus and R. flavifaciens, are genetically independent or that they are ecologically distinguishable, so that the possibility of an exchange of genetic 
material between them cannot be excluded. Again, the importance to be attached to characters such as morphology and production of ethanol is not clear. These characters are consistently associated but their significance in the life of the bacterial cell is obscure. In these circumstances a technique which classifies strains on the basis of their overall similarity is of value because it embodies all the information without weighting it. Such an Adansonian classification is particularly suited to the present study, where the relationship between overall biochemical type and serological type was investigated. Numerical taxonomy provides the methods necessary for this treatment of the data.

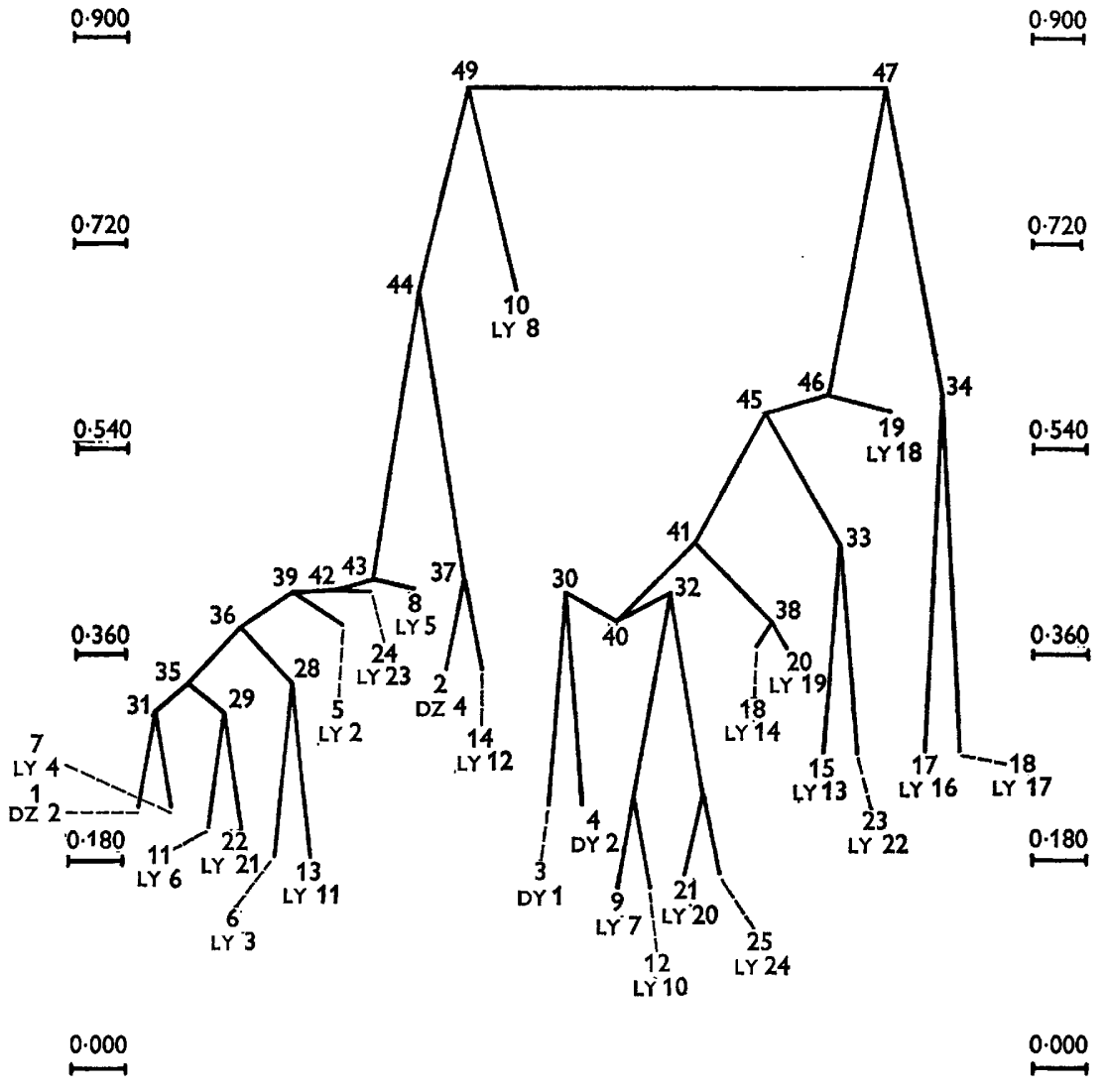

Fig. 1. Numerical classification of twenty-five strains of the genus Ruminococcus.

The data presented in Tables 2 and 3 together with a summary of those in Table 4 were analysed by using a Fortran program 'MULTIST' for Control Data 3600 computer (C.S.I.R.O. Computing Research Section, technical note no. 14). The rationale of the method and the formulae used are given by Williams \& Lance (1965). This program accepted qualitative, multi-state and quantitative data, calculated a non-metric coefficient and utilized centroid sorting. Gram-reaction results were treated as threestate multi-state attributes since Gram-variable $( \pm)$ is no less a feature of the organism than is Gram-positive or Gram-negative. Arrangement and pigment production were 
similarly treated. Gas production was treated as a multi-state variable because here \pm represented 'slight gas production'. In the nutritional data results indicated as \pm were treated as unknown because it was doubtful whether the medium had been used for growth. These data were treated as qualitative in common with 'growth in Bryant \& Robinson medium', 'sugar fermented' and 'production of reducing sugars'. Final pH value and 'fermentation end products' were treated as quantitative data. The affinities which were demonstrated by this treatment of the data are presented as a dendrogram in which the ordinate represents the value of the similarity coefficient (Fig. 1). Here groups 9 and 12 represent the two most similar strains, their degree of similarity being represented by their positions relative to the ordinate scale. Together they constitute a new group 26 . At the 0.238 degree of similarity group 27 can be added to group 26, making a new group 32. The perpendicular distance between 26 and 32 represents the decrease in similarity which must be accepted before further strains can be clustered with group 26. This process is continued until at a low degree of similarity all strains can be grouped together.

The dendrogram comprises two main branches corresponding to the existing species and two intermediate groups. The branch represented by group 44 includes all the strains classified as Ruminococcus albus except LY 16, which is now classed as an intermediate in group 34. It is evident that the differences which prevented strains DZ 2 and LY 23 from being considered members of this group were minor. The dendrogram shows that these two strains closely resembled accepted members of the species and should logically be included with it. The branch represented by group 45 comprises all strains classed as R. flavifaciens and includes strains LY 13 and LY 19. Strain LY 18 can also be included for a small change in similarity coefficient. Hence group 46 is considered to represent $R$. flavifaciens strains. It is concluded that numerical classification of these strains agrees closely with that derived by the established methods. But the numerical method justifies the assignment of intermediate strains to appropriate species and permits an assessment of the degree of relationship between members of the same group. Thus $R$. albus (group 44) is, in general, more homogeneous than $R$. flavifaciens (group 46) although a considerable increase in similarity index is required to accommodate group 37 within group 44. Comparison of Table 2 with Fig. 1 permits the extraction of characters typical of the two species.

Ruminococcus albus (11 strains). All were diplococci. When grown on cellulose they produced butyrate, propionate, formate and ethanol. In addition 10 of 11 produced acetate and 9 of 11 produced lactate. Most strains (10 of 11) were capable of growth without unidentified growth factors which occur in rumen liquor.

Ruminococcus flavifaciens (11 strains). All were streptococci. Grown on cellulose they produced formate but not ethanol. Most strains ( 9 of 11) produced succinate and lactate, and 10 of 11 produced acetate. Butyrate and propionate were usually not produced. A minority (4 of 11) of strains were capable of growth without unidentified factors which occur in rumen liquor.

The authors thank Dr G. N. Lance (C.S.I.R.O. Computing Research Section, Canberra, A.C.T.) for numerical treatment of the data, and $\mathrm{Mr} \mathrm{J}$. Wilcher for technical assistance with the estimation of fermentation products. 


\section{REFERENCES}

Allison, M. J. \& Bryant, M. P. (1963). Biosynthesis of branched-chain amino acids from branchedchain fatty acids by rumen bacteria. Arch. Biochem. Biophys. 101, 269.

Allison, M. J., BryanT, M. P. \& Doetsch, R. N. (1962). Studies on the metabolic function of branched-chain volatile fatty acids, growth factors for ruminococci. J. Bact. 83, 523 .

AYERs, W. A. (1958). Nutrition and physiology of Ruminococcus flavifaciens. J. Bact. 76, 504.

BRYANT, M. P. (1959). Bacterial species of the rumen. Bact. Rev. 23, 125.

BRYANT, M. P. (1963). Symposium on microbial digestion in ruminants. Identification of groups of anaerobic bacteria active in the rumen. J. anim. Sci. 22, 801.

Bryant, M. P. \& Burkey, L. A. (1953). Cultural methods and some characteristics of some of the more numerous groups of bacteria in the bovine rumen. J. Dairy Sci. 36, 205.

BRYANT, M. P. \& Robinson, I. M. (1961 a). Some nutritional requirements of the genus Ruminococcus. Appl. Microbiol. 9, 91.

Bryant, M. P. \& Robinson, I. M. (1961 b). Studies on the nitrogen requirements of some ruminal cellulolytic bacteria. Appl. Microbiol. 9, 96.

BRyANT, M. P. \& Robinson, I. M. (1961c). An improved nonselective culture medium for ruminal bacteria and its use in determining diurnal variation in numbers of bacteria in the rumen. J. Dairy Sci. 44, 1446.

Bryant, M. P. \& Robinson, I. M. (1962). Some nutritional characteristics of predominant culturable ruminal bacteria. J. Bact. 84, 605 .

Bryant, M. P. \& RoBinson, I. M. (1963). Apparent incorporation of ammonia and amino acid carbon during growth of selected species of ruminal bacteria. J. Dairy Sci. 46, 150.

Bryant, M. P., Small, N., Bouma, C. \& CHU, H. (1958a). Species of succinic acid-producing anaerobic bacteria of the bovine rumen. Bacteriodes ruminicola N.sp. and Succinomonas amylolytica the new genus and species. J. Bact. 76, 15.

Bryant, M. P., Small, N., Bouma, C. \& Robinson, I. M. (1958b). Characteristics of ruminal anaerobic cellulolytic cocci and Cillobacterium cellulosolvens N.sp. J. Bact. 76, 529.

BÜCHER, Th. \& REDETZKI, H. (1951). Eine spezifische photometrische Bestimmung von Äthylalkohol auf fermentativem Wege. Klin. Wschr. 29, 615.

DEHORITY, B. A. (1963). Isolation and characterization of several cellulolytic bacteria from in vitro rumen fermentations. J. Dairy Sci. 46, 217.

FLETCHER, D. W. (1956). Studies on the growth requirements of a cellulolytic coccus from the bovine rumen. Ph.D. thesis, State College of Washington, Pullman, Washington.

Gall, L. S. \& Huhtanen, C. N. (1951). Criteria for judging a true rumen organism and a description of five rumen bacteria. J. Dairy Sci. 34, 353.

Halliwell, G. (1957). Cellulolytic preparations from micro-organisms of the rumen and from Myrothecium verrucaria. J. gen. Microbiol. 17, 166.

Hawk, P. B., Oser, B. L. \& Summerson, W. H. (1954). Practical Physiological Chemistry, 13th ed. London: J. and A. Churchill Ltd.

Hungate, R. E. (1950). The anaerobic mesophilic cellulolytic bacteria. Bact. Rev. 14, 1.

Hungate, R. E. (1957). Microorganisms in the rumen of cattle fed a constant ration. Can. J. Microbiol. 3, 289.

KISTNER, A. \& Gouws, L. (1964). Cellulolytic cocci occurring in the rumen of sheep conditioned to lucerne hay. J. gen. Microbiol. 34, 447.

Leng, R. A. \& ANNison, E. F. (1963). Metabolism of acetate, propionate and butyrate by sheep liver slices. Biochem. J. 86, 319.

NeISH, A. C. (1952). Analytical Methods for Bacterial Fermentations, 2nd revision. Saskatoon, Nat. Research Council of Canada, Report no. 46-8-3.

SiJPesteiJn, A. K. (1948). Cellulose-decomposing bacteria from the rumen of cattle. Ph.D. thesis, University of Leiden.

SiJPESTEIJN, A. K. (1951). On Ruminococcus flavifaciens, a cellulose-decomposing bacterium from the rumen of sheep and cattle. J. gen. Microbiol. 5, 869.

Williams, W. T. \& LANCE, G. N. (1965). Logic of computer-based intrinsic classifications. Nature, Lond. 207, 159. 